\title{
Association study in Alzheimer's disease of single nucleotide polymorphisms implicated with coffee consumption
}

\author{
Victor Junji Yamamoto1,2, Vanessa de Jesus Rodrigues de Paula1,2, Orestes Vicente Forlenza1,2, \\ Bernardo dos Santos 3 , Daniel Shikanai KerR ${ }^{1,2}$
}

1 Laboratory of Neuroscience (LIM-27), Department and Institute of Psychiatry, Faculty of Medicine, University of Sao Paulo (Ipq-FMUSP), Sao Paulo, Brazil. 2 Center for Interdisciplinary Research on Applied Neurosciences (NAPNA), USP, São Paulo, Brazil.

3 Research Assistance Service, School of Nursing, USP, São Paulo, Brazil.

Received: 4/16/2015 - Accepted: 4/27/2015

DOI: 10.1590/0101-60830000000050

\begin{abstract}
Background: There is evidence from animal and in vitro models of the protective effects of caffeine in Alzheimer's disease. The suggested mechanisms through which caffeine may protect neurons against Alzheimer's disease pathology include the facilitation of beta-amyloid clearance, upregulation of cholinergic transmission, and increased neuronal plasticity and survival. Epidemiological studies support that Alzheimer's disease patients consume smaller amounts of coffee beverages throughout their lives as compared to age-matched cognitively healthy individuals. Objective: The aim of the present study was to determine whether the negative association between Alzheimer's disease and coffee consumption may be influenced by a common genetic predisposition, given the fact that the pattern of coffee consumption is determined by both environmental and genetic factors. Method: We conducted an in silico search addressing the association between genetic polymorphisms related to coffee consumption and the diagnosis of Alzheimer's disease. We further investigated the interactions between genes located in regions bearing these polymorphisms. Results: Our analysis revealed no evidence for a genetic association (nor interaction between related proteins) involving coffee consumption and Alzheimer's disease. Discussion: The negative association between Alzheimer's disease and coffee consumption suggested by epidemiological studies is most likely due to environmental factors that are not necessarily regulated by genetic background.
\end{abstract}

Yamamoto VJ et al. / Arch Clin Psychiatry. 2015;42(3):69-73

Keywords: Caffeine, Alzheimer's disease, SNP.

\section{Introduction}

More than $90 \%$ of new therapeutics developed for Alzheimer's disease (AD) have been unsuccessful 1 . The lack of an effective treatment contributed to increase the attention to life style and dietary interventions that could modify the etiology of the disease ${ }^{2}$. Epidemiological studies have indicated a negative association between coffee consumption and $\mathrm{AD}$, suggesting that caffeine may have neuroprotective effects against cognitive decline ${ }^{2-5}$. This xanthine-derived substance, highly concentrated in coffee, is a stimulant to the central nervous system that may be beneficial against certain deficits associated with $\mathrm{AD}^{3,6,7}$. Putative mechanisms for caffeine neuroprotection in $\mathrm{AD}$ include the facilitation of beta-amyloid clearance ${ }^{7,8}$, and the upregulation of cholinergic neurotransmission ${ }^{9}$ and/or signalling pathways related to neuronal plasticity and survival ${ }^{10-12}$. Most of those effects are probably mediated the stimulation of adenosine receptors ${ }^{13}$. However, evidence of beneficial effects of caffeine in human cognition is largely derived from epidemiological associations, with scarce direct evidence for the protective effects of coffee/caffeine in patients with $\mathrm{AD}^{14}$. Coffee consumption is determined by both environmental and genetic factors. Environmental factors related to coffee consumption include mainly age and sex, but it is also influenced by geographical location, religious preferences and socioeconomic conditions. Great effort has been made to identify genetic factors involved in coffee intake. Meta-analyses of genome-wide association indicated some common genetic variants that influence coffee consumption, localized in CYP1A1/CYP1A2, NRCAM and AHR genes ${ }^{15-17}$. AD is a multifactorial neurodegenerative disorder resulting from the interaction between multiple genetic and environmental factors ${ }^{18-20}$. Since there are genetic factors associated with both $\mathrm{AD}$ and coffee consumption, one cannot rule out the possibility that the negative association observed in epidemiological studies are due to a common genetic background, or even interactions among related gene products. In the present study, our aim was to evaluate genetic associations of single nucleotide polymorphisms (SNP) related to coffee consumption in the Alzheimer's Disease Neuroimaging Initiative (ADNI) cohort, comprising patients with $\mathrm{AD}$ or mild cognitive impairment (MCI) and healthy age-matched controls. Also to investigate possible interactions among the products of genes associated with $\mathrm{AD}$ and those located near the coffee consumption SNP.

\section{Methods}

\section{Sample}

Data used in the preparation of this article were obtained from the ADNI database (adni.loni.ucla.edu). The ADNI was launched in 2003 by the National Institute on Aging (NIA), the National Institute of Biomedical Imaging and Bioengineering (NIBIB), the Food and Drug Administration (FDA), private pharmaceutical companies and non-profit organizations, as a $\$ 60$ million, 5-year public-private partnership. The primary goal of ADNI has been to test whether serial magnetic resonance imaging (MRI), positron emission tomography (PET), other biological markers, and clinical and neuropsychological assessment can be combined to measure the progression of MCI and early AD. Determination of sensitive and specific markers of very early $\mathrm{AD}$ progression is intended to aid researchers and clinicians to develop new treatments and monitor their effectiveness, as well as lessen the time and cost of clinical trials.

The Principal Investigator of this initiative is Michael W. Weiner, MD, VA Medical Center and University of California - San Francisco. $\mathrm{ADNI}$ is the result of efforts of many co-investigators from a broad range of academic institutions and private corporations, and subjects have been recruited from over 50 sites across the U.S. and Canada. 
The initial goal of ADNI was to recruit 800 subjects but ADNI has been followed by ADNI-GO and ADNI-2. To date these three protocols have recruited over 1,500 adults, ages 55 to 90 , to participate in the research, consisting of cognitively normal older individuals, people with early or late MCI, and people with early AD. The follow up duration of each group is specified in the protocols for ADNI-1, ADNI-2 and ADNI-GO. Subjects originally recruited for ADNI-1 and ADNI-GO had the option to be followed in ADNI-2. For upto-date information, see www.adni-info.org.

A total of 757 individuals were genotyped using the Illumina Human Genome 610 Quad BeadChips in the ADNI database downloaded in November 2011. We excluded individuals with less than 65 years of age, since they might correspond to the early onset forms of $\mathrm{AD}$. The most recent clinical data of those subjects, at the time, revealed 198 healthy controls (CT), 193 classified as MCI and 318 diagnosed with $\mathrm{AD}$. All those individuals had less than $10 \%$ missing genotypes. There was no information regarding coffee consumption in the ADNI database at the time of download.

Genotype data of SNPs that had been strongly associated with coffee consumption ${ }^{15-17}$ was retrieved from the ADNI database. From the chosen SNPs (rs12148488, rs2470893, rs2472297, rs2472304, rs382140, rs4410790, rs5751876, rs6495122, rs762551), only rs5751876 was not present in the ADNI database. The remaining SNPs passed our quality control with a call rate above $90 \%$ and minor allele frequency greater than 2\%. rs16868941 was in Hardy Weinberg disequilibrium ( $p<0.10$; table 1 ) and was excluded from further analysis. Quality control analysis was performed with PLINK v1.07 and R software.

Firstly, we compared the genome location of the coffee consumption and AD SNPs from the top 10 associated SNPs in the repository of meta-analyses AlzGene (last updated 18th April 2011 - http:// www.alzgene.org) ${ }^{21}$.

We used the Search Tool for the Retrieval of Interacting Genes/ Proteins (STRING; http://string-db.org) 22 to investigate known protein interactions and pathway enrichment among the coffee consumption genes (up to $50 \mathrm{~kb}$ of distance, if the SNP is not inside

Table 1. Coffee consumption SNPs - List of SNPs associated with coffee consumption, nearby genes (up to $50 \mathrm{~kb}$, if the SNP is not inside a gene) and chromosome they are located - Minor allele frequency (MAF) and $p$ value for Hardy-Weinberg equilibrium (HWE; In bold $p<0.10$ ) for each SNP in the Alzheimer's Disease Neuroimaging Initiative (ADNI) cohort is also presented

\begin{tabular}{|c|c|c|c|c|c|c|c|}
\hline SNP & Genes & $\mathrm{Chr}$ & $\operatorname{MAF}(\%)$ & HWE & $\begin{array}{l}\text { HWE } \\
\text { Control }\end{array}$ & $\begin{array}{l}\text { HWE } \\
\mathrm{MCl}\end{array}$ & $\begin{array}{c}\text { HWE } \\
A D\end{array}$ \\
\hline rs12148488 & PPCDC & 15 & G (49) & 0.275 & 1.000 & 0.885 & 0.033 \\
\hline rs16868941 & NCALD & 8 & $A(19)$ & 0.063 & - & 1.000 & 0.848 \\
\hline rs2470893 & $\begin{array}{c}\text { CYP1A1, } \\
\text { CYP1A2, } \\
\text { EDC3 }\end{array}$ & 15 & $A(28)$ & 0.179 & 0.706 & 0.469 & 0.144 \\
\hline rs2472297 & $\begin{array}{l}\text { CYP1A1, } \\
\text { CYP1A2, } \\
\text { EDC3, CSK }\end{array}$ & 15 & $T(21)$ & 0.286 & 0.622 & 0.684 & 0.877 \\
\hline rs2472304 & CYP1A2 & 15 & G (37) & 0.140 & 0.140 & 0.522 & 0.286 \\
\hline rs382140 & $\begin{array}{l}\text { LAMB4, } \\
\text { NRCAM }\end{array}$ & 7 & $A(17)$ & 0.379 & 0.507 & 0.464 & 0.535 \\
\hline rs4410790 & AHR & 7 & $T(41)$ & 0.940 & 0.659 & 0.042 & 0.347 \\
\hline rs5751876 & AD0RA2A & 22 & - & - & & & \\
\hline rs6495122 & $\begin{array}{c}\text { CPLX3, } \\
\text { ULK3, } \\
\text { SCAMP2, } \\
\text { MPI, } \\
\text { LMAN1L, } \\
\text { CSK }\end{array}$ & 15 & $A(45)$ & 0.825 & 0.774 & 0.020 & 0.056 \\
\hline rs762551 & CYP1A2 & 15 & $C(27)$ & 0.855 & 0.733 & 0.698 & 1.000 \\
\hline
\end{tabular}

a gene) and the top $10 \mathrm{AD}$ associated genes from Alzgene ${ }^{21}$. Significance for this analysis was set as $\mathrm{p}<0.05$ after FDR correction.

APOE alleles frequencies were retrieved from AlzGene metaanalysis and ADNI database. We used a chi-square test in LibreOffice Calc 3.5 (significance, $p<0.05$ ) to compare the frequencies in control and $\mathrm{AD}$ individuals in those sets.

Association of each caffeine SNP among controls, MCI or AD was tested with Wald test for multinomial logistic regression controlled by age, gender, years of education and presence of the e4 allele of APOE. We also tested the model considering a dominant (MAF allele carrier vs non-carrier) or recessive (homozygous for the MAF allele vs other genotypes) pattern of inheritance for each MAF allele of each SNP. Significance was set as $\mathrm{p}<0.0018$, to correct for multiple comparisons with the conservative Bonferroni method. We also tested for association of controls, MCI or AD with caffeine SNP, age, gender, years of education and APOE genotype with a classification and regression tree (CART). These analyses were conducted with the aid of the R software version 2.15.2.

\section{Results}

Demographic data is summarized in table 2. The MCI group had significantly fewer females than control $(\mathrm{p}=0.010)$ or $\mathrm{AD}(\mathrm{p}=$ 0.049 ) groups. AD subjects on average had fewer years of education than controls $(p=0.019)$. There was no difference in APOE alleles frequencies between ADNI and AlzGene (table 1, p > 0.90). We observed a strong association of the e4 allele of APOE and AD tested with a general linear model controlled by age, gender and education compared to healthy controls $\left(\mathrm{p}=2.079 \times 10^{-17}\right)$. Also, presence of APOE e4 in MCI was significantly different from both healthy controls $(\mathrm{p}=0.0005)$ and $\mathrm{AD}$ patients $\left(\mathrm{p}=4.908 \times 10^{-7}\right)$. No association was observed between the coffee consumption SNPs and AD, for the three different scenarios tested (general, dominant MAF allele and recessive MAF allele models; table 3). CART analysis showed no association of coffee consumption SNPs and the three groups after cross validation. However, if we exclude MCI from the analysis, rs6495122 appears as

Table 2. Summarized demographic data of the ADNI individuals selected for this paper and $\mathrm{APOE}^{*} \mathrm{e} 4$ frequencies for $\mathrm{ADNI}$ and AlzGene cohort (\# $p<0.05$ in Fisher exact test when compared to either Healthy control or Alzheimer's Disease groups. ${ }^{*} p<0.05$ in ANOVA, with post TUKEY-HSD when compared to Healthy control group. \& $p<0.05$ in Fisher exact test when compared to Healthy control)

\begin{tabular}{|l|c|c|c|}
\hline & Healthy control & $\begin{array}{c}\text { Mild cognitive } \\
\text { impairment }\end{array}$ & Alzheimer's disease \\
\hline $\begin{array}{l}\text { Gender (\% } \\
\text { female) }\end{array}$ & 45.9 & $33.2 \#$ & 42.1 \\
\hline $\begin{array}{l}\text { Age (mean } \\
\pm \text { SD) }\end{array}$ & $79.2 \pm 5.5$ & $78.9 \pm 6.6$ & $79.3 \pm 5.8$ \\
\hline $\begin{array}{l}\text { Age at } \\
\text { diagnostics } \\
\text { (mean } \pm \text { SD) }\end{array}$ & - & - & $75.0 \pm 5.9$ \\
\hline $\begin{array}{l}\text { Years of } \\
\text { education } \\
\text { (mean } \pm \text { SD) }\end{array}$ & $16.0 \pm 2.8$ & $15.6 \pm 3.2$ & $15.2 \pm 3.1^{*}$ \\
\hline $\begin{array}{l}\text { Handedness } \\
\text { (\% right } \\
\text { handed) }\end{array}$ & 91.9 & 94.3 & 93.7 \\
\hline $\begin{array}{l}\text { Ethnic } \\
\text { background } \\
\text { (\% } \\
\text { Caucasian) }\end{array}$ & 91.4 & 90.0 & 91.8 \\
\hline $\begin{array}{l}\text { APOE* } \\
\text { ADNI (\%) }\end{array}$ & 15 & $25 \#$ & $42 \&$ \\
\hline AlzGene & 14 & - & $38 \&$ \\
\hline
\end{tabular}


a relevant factor to classify between controls and $\mathrm{AD}$ (Figure 1). Our analysis of protein interactions with STRING revealed no known interactions among coffee consumption associated proteins and the $\mathrm{AD}$ proteins. As can be seen in figure 2 the genes for $\mathrm{AD}$ and for coffee consumption had no significant interaction (with a confidence greater than 0.5 in STRING algorithm). Also, enrichment analysis of KEGG pathways showed only a significant $(\mathrm{p}=0.038$ after FDR correction) group of AD associated genes (PSEN1, PSEN2, APP and APOE).

Table 3. Association of $A D$ and Coffee consumption SNPs in the ADNI cohort - Association of AD and Coffee consumption SNPs in the ADNI cohort was evaluated with a multinomial logistic regression model controlled by age, gender, years of education and presence of the e4 allele of APOE followed by Wald test - Dominant and Recessive columns, correspond to $\mathrm{p}$ value of the model, when testing for dominant (MAF allele carrier vs non-carrier) and recessive (homozygous for the MAF allele vs other genotypes) pattern of association. General is the p value with no pattern of inheritance considered. Significance was set as $p<0.0018$, to correct for multiple comparisons with the conservative Bonferroni method

\begin{tabular}{|c|c|c|c|c|c|c|c|}
\hline \multirow{2}{*}{ SNP } & & & \multirow{2}{*}{ General } & \multicolumn{2}{|c|}{ Dominant } & \multicolumn{2}{|c|}{ Recessive } \\
\hline & & & & Vs Control & $\mathrm{AD}$ vs $\mathrm{MCl}$ & Vs Control & $\mathrm{AD}$ vs $\mathrm{MCl}$ \\
\hline rs12148488 & $\begin{array}{l}\text { C: } \\
\text { MCl: } \\
\text { AD: }\end{array}$ & $\begin{array}{l}\text { GG(23); GT(50); TT(27) } \\
\text { GG(26); GT(51); TT(23) } \\
\text { GG(27); GT(44); TT(29) }\end{array}$ & 0.431 & $\begin{array}{c}- \\
0.324 \\
0.849 \\
\end{array}$ & 0.200 & $\begin{array}{c}- \\
0.364 \\
0.218 \\
\end{array}$ & $\begin{array}{c}- \\
0.779 \\
\end{array}$ \\
\hline rs2470893 & $\begin{array}{l}\mathrm{C}: \\
\mathrm{MCl}: \\
\mathrm{AD}: \\
\end{array}$ & $\begin{array}{l}\text { CC(57); CT(36); TT(7) } \\
\text { CC(51); СТ(43); TT(6) } \\
\text { CC(50); СТ(39); TT(11) }\end{array}$ & 0.392 & $\begin{array}{c}- \\
0.247 \\
0.249 \\
\end{array}$ & $\begin{array}{c}- \\
0.934\end{array}$ & $\begin{array}{c}- \\
0.738 \\
0.330\end{array}$ & $\begin{array}{c}- \\
0.166\end{array}$ \\
\hline rs2472297 & $\begin{array}{l}\text { C: } \\
\text { MCl: } \\
\text { AD: }\end{array}$ & $\begin{array}{l}\text { CC(69); CT(28); ТT(3) } \\
\text { CC(60); СТ(34); ТT(6) } \\
\text { CC(58); CT(36); ТT(6) }\end{array}$ & 0.315 & $\begin{array}{c}- \\
0.085 \\
0.446\end{array}$ & $\begin{array}{c}- \\
0.847\end{array}$ & $\begin{array}{c}- \\
0.459 \\
0.624\end{array}$ & $\begin{array}{c}- \\
0.733\end{array}$ \\
\hline rs2472304 & $\begin{array}{l}\mathrm{C}: \\
\mathrm{MCl}: \\
\mathrm{AD}:\end{array}$ & $\begin{array}{l}\text { CC(19); СТ(43); TT(38) } \\
\text { CC(11); СТ(47); TT(42) } \\
\text { CC(17); СТ(44); TT(39) }\end{array}$ & 0.209 & $\begin{array}{c}- \\
0.324 \\
0.482 \\
\end{array}$ & $\begin{array}{c}- \\
0.722 \\
\end{array}$ & $\begin{array}{c}- \\
0.035 \\
0.752\end{array}$ & $\begin{array}{c}- \\
0.052\end{array}$ \\
\hline rs382140 & $\begin{array}{l}\text { C: } \\
\text { MCl: } \\
\text { AD: }\end{array}$ & $\begin{array}{l}\text { CC(65); CT(30); ТT(5) } \\
\text { CC(68); CT(28); TT(4) } \\
\text { CC(71); CT(26); ТT(3) }\end{array}$ & 0.741 & $\begin{array}{c}- \\
0.559 \\
0.174 \\
\end{array}$ & $\begin{array}{c}- \\
0.444 \\
\end{array}$ & $\begin{array}{c}- \\
0.953 \\
0.698 \\
\end{array}$ & $\begin{array}{c}- \\
0.652\end{array}$ \\
\hline rs4410790 & $\begin{array}{l}\text { C: } \\
\text { MCl: } \\
\text { AD: }\end{array}$ & $\begin{array}{l}A A(17) ; A G(47) ; G G(36) \\
A A(17) ; A G(57) ; G G(26) \\
A A(17) ; A G(45) ; G G(38)\end{array}$ & 0.049 & $\begin{array}{c}- \\
0.011 \\
0.782 \\
\end{array}$ & $\overline{-} .012$ & $\begin{array}{c}- \\
0.859 \\
0.758 \\
\end{array}$ & $\begin{array}{c}- \\
0.901\end{array}$ \\
\hline rs6495122 & $\begin{array}{l}\mathrm{C}: \\
\mathrm{MCl}: \\
\mathrm{AD}:\end{array}$ & $\begin{array}{l}\text { GG(31); GT(48); TT(21) } \\
\text { GG(28); GT(58); TT(14) } \\
\text { GG(32); GT(44); TT(24) }\end{array}$ & 0.024 & $\begin{array}{c}- \\
0.629 \\
0.594 \\
\end{array}$ & $\begin{array}{c}- \\
0.280\end{array}$ & $\begin{array}{c}- \\
0.142 \\
0.306\end{array}$ & $\begin{array}{c}- \\
0.010\end{array}$ \\
\hline rs762551 & $\begin{array}{l}\mathrm{C}: \\
\mathrm{MCl}: \\
\mathrm{AD}:\end{array}$ & $\begin{array}{l}\text { AA(49); } \mathrm{AC}(43) ; \mathrm{CC}(8) \\
\mathrm{AA}(57) ; \mathrm{AC}(38) ; \mathrm{CC}(5) \\
\mathrm{AA}(49) ; \mathrm{AC}(42) ; \mathrm{CC}(9)\end{array}$ & 0.290 & $\begin{array}{l}- \\
0.110 \\
0.618 \\
\end{array}$ & $\begin{array}{c}- \\
0.211 \\
\end{array}$ & $\begin{array}{c}- \\
0.386 \\
0.433 \\
\end{array}$ & $\begin{array}{c}- \\
0.099 \\
\end{array}$ \\
\hline
\end{tabular}

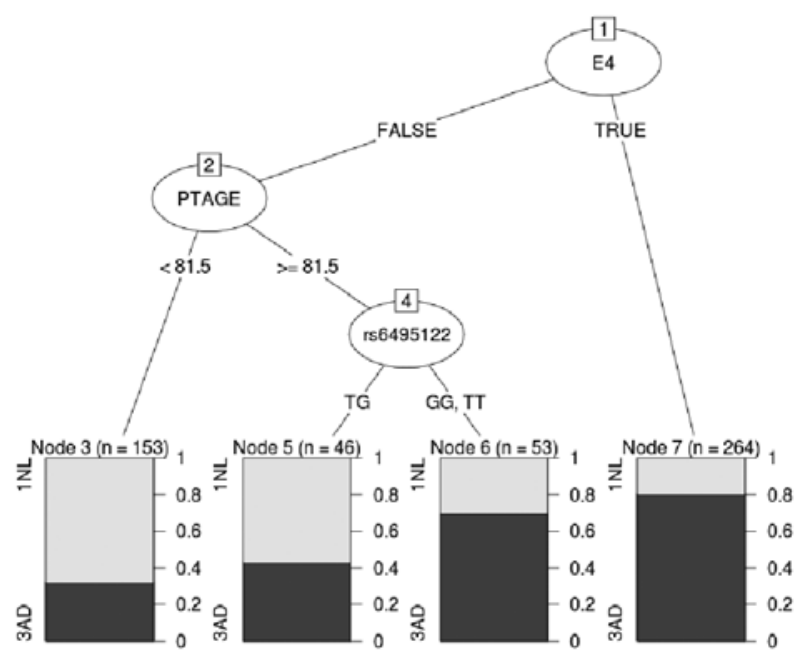

Figure 1. Coffee consumption SNP (rs6495122) improves the classification between healthy controls (1 NL) and Alzheimer's disease patients (3AD) in a classification and regression tree. Main factors for classification were presence of e4 allele of APOE (E4) and age (PTAGE).

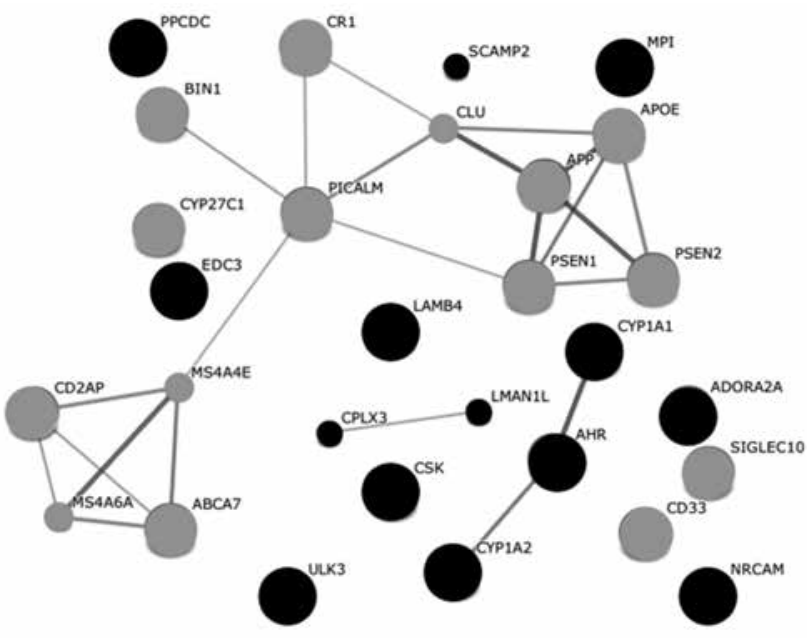

Figure 2. Network of interactions for the corresponding genes whithin $50 \mathrm{~kb}$ of the selected SNPs. Adapted from image generated with STRING with a confidence of 0.5 in June 2013. For better viewing we painted the nodes for Alzheimer's disease genes in gray and Coffee consumption in black. Stronger interactions are represented with thicker lines. Bigger nodes indicate those for which the protein structure has been elucidated. 


\section{Discussion}

Our results suggest that it is unlikely that the negative association between coffee consumption and $\mathrm{AD}$ prevalence is due to a common genetic background, at least between the regions compared here. We found no association between coffee consumption SNPs and AD, also there was no correlation between genetic regions and gene products for those two characteristics.

Firstly, none of the evaluated coffee consumption SNPs ${ }^{15-17}$ is genetically near any of the most associated SNPs for $\mathrm{AD}^{21}$. This rule out the possibility of linkage disequilibrium between them. Also, there was no significant association between coffee consumption SNPs and $\mathrm{AD}$ in general, dominant MAF allele and recessive MAF allele models in the ADNI cohort. Also, rs6495122 appears as a relevant factor for classification in CART only after APOE genotype and age, two already known risk factors for $\mathrm{AD}^{19}$. Lastly, we found no known interaction between the gene products considered for coffee consumption and $\mathrm{AD}$, which might have suggested an indirect association. Cornelis et al. mentioned in his meta-analysis that the coffee consumption SNPs did not showed before in large AD GWAS studies ${ }^{17}$. This is the first attempt to investigate if there is a genetic correlation behind the evidence for a protective effect of coffee in AD. Larger cohorts with genetic and coffee consumption information might be required to further elucidate this question.

Experimental data suggests that caffeine derivates have neurobiological benefits on cognition and $\mathrm{AD}$ pathology. It probably results from the effects of these substances on signalling pathways related to $\mathrm{AD}$ pathophysiology and/or neuronal resilience.

Animal models suggested that caffeine administration was associated with reduction of both soluble and deposited amyloid- $\beta$ (A $\beta)$ in brain ${ }^{7}$. The hydrophobic nature of caffeine allows its rapid absorption through all biological membranes, rendering it is rapidly absorbed into the bloodstream and through the blood-brain barrier ${ }^{23}$. In vitro studies, showed that caffeine increases basal synaptic transmission, but does not affect LTP, at the same synapses ${ }^{24}$. However, the concentrations of caffeine required to exert these effects, are several orders of magnitude higher than the plasmatic concentration attained by ingestion of moderate amounts of coffee ${ }^{17,25,26}$. The only pharmacological mechanism known for caffeine in the low micromolar range is the antagonism of adenosine receptors, namely adenosine $\mathrm{A} 1$ and $\mathrm{A} 2 \mathrm{~A}$ receptors and maybe adenosine $\mathrm{A} 3$ receptors ${ }^{13,16,27,28}$, leading to many downstream changes, including alterations in gene expression. The blockade of adenosine receptors confers neuroprotection against $A \beta^{6}$, but the underlying mechanisms by which caffeine reduces the relative risk for $\mathrm{AD}$ are not well elucidated. Adenosine A1 receptors in the cerebral cortex and hippocampus are primarily located on pre-synaptic terminals. Caffeine can block those receptors in cholinergic terminals which increases extracellular levels of acetylcholine, an important neurotransmitter for cognitive processing, dramatically decreased in the AD brain'. Another plausible hypothesis which could explain the decreasing level of $A \beta$ is based on enhanced clearance of $A \beta$ from the brain due to upregulation of P-glycoprotein (P-gp) induced by caffeine ${ }^{8}$. P-gp is an adenosine triphosphate (ATP) dependent transporter protein, which acts as an efflux pump. This transporter is located mainly in luminal membrane of brain capillary endothelium comprising the blood-brain-barrier, and is responsible for extrusion of drugs and toxins from the brain, including $A \beta^{29}$. An increasing number of studies further suggest that alterations in expression and functional activity of P-gp contribute to the accumulation of $A \beta$ in the brain, and lead to increased risk for developing $\mathrm{AD}^{30}$. A third possible mechanism by which caffeine could ameliorate $\mathrm{AD}$ prognosis is by acting in neuronal plasticity and survival. Caffeine induced both elongation of existing dendritic spines and new spine formation in primary cultured hippocampal neurons ${ }^{11}$. Also, long-term caffeine treatment in $\mathrm{AD}$ transgenic mice decreased pro-inflammatory cytokines such as TNFa and IFN $\gamma$ in the brain ${ }^{10}$. Taken together with its beneficial effects on signal transduction $^{12}$, these results suggest an important role for caffeine in neuronal plasticity and survival. There are also other hypotheses about the mechanisms involved in neuroprotection by caffeine ${ }^{31}$, however the exactly mechanisms are not completely understood8.

There is no specific information of coffee consumption in the ADNI database. This is a limitation of the present analysis, since the evaluated SNPs might not correspond directly to coffee consumption in this sample. Also, we cannot rule out that the lack of significance might be due to a lack of power, because of the sample size. On the other hand, the ADNI sample had frequencies of APOE allele similar to the general population and we also replicated the strong association between APOE e4 allele and AD. These results indicate there were no sampling errors.

If we consider a less conservative threshold of $p<0.05$, there are some observable differences in the MCI group compared to $\mathrm{AD}$ and/or healthy controls, rs4410790 (general and dominant models), rs6495122 (general and recessive models) and rs2472304 (recessive model). As mentioned, rs6495122 also appears as a relevant factor for the CART. Interestingly, the daily dose associated with cognitive protection is 3 to 5 cups of coffee. Depending on preparation and coffee type this dose corresponds to $210-1,100 \mathrm{mg}$ of caffeine per day5. In comparison, the coffee consumption SNPs are associated with a change of less than $1 \mathrm{mg} /$ day in a general model, but a maximum $44 \mathrm{mg}$ per day difference between genotypes ${ }^{17}$. Given the effects magnitude, these coffee consumption genetic variants may not be a determinant factor in the estimated protective coffee dose. However, they might act as outcome modifiers as a result of the direct and indirect interaction with other genetic and environmental factors. Thus, it might be a good approach to introduce those SNPs as covariables in future studies of coffee and caffeine consumption, cognitive deficit and AD.

\section{Acknowledgements}

Data collection and sharing for this project was funded by the Alzheimer's Disease Neuroimaging Initiative (National Institutes of Health Grant U01 AG024904). ADNI is funded by the National Institute on Aging, the National Institute of Biomedical Imaging and Bioengineering, and through generous contributions from the following: Alzheimer's Association; Alzheimer's Drug Discovery Foundation; BioClinica, Inc.; Biogen Idec Inc.; Bristol-Myers Squibb Company; Eisai Inc.; Elan Pharmaceuticals, Inc.; Eli Lilly and Company; F. Hoffmann-La Roche Ltd and its affiliated company Genentech, Inc.; GE Healthcare; Innogenetics, N.V.; IXICO Ltd.; Janssen Alzheimer Immunotherapy Research \& Development, LLC.; Johnson \& Johnson Pharmaceutical Research \& Development LLC.; Medpace, Inc.; Merck \& Co., Inc.; Meso Scale Diagnostics, LLC.; NeuroRx Research; Novartis Pharmaceuticals Corporation; Pfizer Inc.; Piramal Imaging; Servier; Synarc Inc.; and Takeda Pharmaceutical Company. The Canadian Institutes of Health Research is providing funds to support ADNI clinical sites in Canada. Private sector contributions are Rev November 7, 2012 facilitated by the Foundation for the National Institutes of Health (www.fnih.org). The grantee organization is the Northern California Institute for Research and Education, and the study is coordinated by the Alzheimer's Disease Cooperative Study at the University of California, San Diego. ADNI data are disseminated by the Laboratory for Neuro Imaging at the University of California, Los Angeles. This research was also supported by NIH grants P30 AG010129 and K01 AG030514.

The Laboratory of Neuroscience (LIM-27) receives financial support from FAPESP, Fundação de Amparo à Pesquisa do Estado de São Paulo, and ABADHS, Associação Beneficente Alzira Denise Hertzog da Silva.

\section{References}

1. Cummings JL, Morstorf T, Zhong K. Alzheimer's disease drug-development pipeline: few candidates, frequent failures. Alzheimers Res Ther 2014 3;6(4):37. Available from: <http://www.pubmedcentral.nih.gov/articlerender.fcgi? artid=4095696\&tool=pmcentrez\&rendertype=abstract. $>$

2. Barberger-Gateau P, Lambert JC, Féart C, Pérès K, Ritchie K, Dartigues JF et al. From genetics to dietetics: the contribution of epidemiology to un- 
derstanding Alzheimer's disease. J Alzheimers Dis. 2013;33 Suppl 1:S45763. Available from: <http://www.ncbi.nlm.nih.gov/pubmed/22683527>.

3. Ritchie K, Carrière I, de Mendonca A, Portet F, Dartigues JF, Rouaud O, et al. The neuroprotective effects of caffeine: a prospective population study (the Three City Study). Neurology. 2007;69(6):536-45. Available from: <http://www.ncbi.nlm.nih.gov/pubmed/17679672>.

4. van Gelder BM, Buijsse B, Tijhuis M, Kalmijn S, Giampaoli S, Nissinen A, et al. Coffee consumption is inversely associated with cognitive decline in elderly European men: the FINE Study. Eur J Clin Nutr. 2007;61(2):22632. Available from: <http://www.ncbi.nlm.nih.gov/pubmed/16929246>.

5. Eskelinen $\mathrm{MH}$, Kivipelto $\mathrm{M}$. Caffeine as a protective factor in dementia and Alzheimer's disease. J Alzheimers Dis. 2010;20 Suppl 1:S167-74. Available from: <http://www.ncbi.nlm.nih.gov/pubmed/20182054>.

6. Canas PM, Porciúncula LO, Cunha GM, Silva CG, Machado NJ, Oliveira $\mathrm{JM}$, et al. Adenosine A2A receptor blockade prevents synaptotoxicity and memory dysfunction caused by beta-amyloid peptides via p38 mitogenactivated protein kinase pathway. J Neurosci. 2009;29(47):14741-51. Available from: <http://www.ncbi.nlm.nih.gov/pubmed/19940169>.

7. Cao C, Cirrito JR, Lin X, Wang L, Wang L, Verges DK, et al. Caffeine suppresses $\beta$-amyloid levels in plasma and brain of Alzheimer's transgenic mice. J Alzheimers Dis. 2009;17(3):681-97. Available from: <http://www. pubmedcentral.nih.gov/articlerender.fcgi? artid=3746074\&tool=pmcent rez\&rendertype $=$ abstract $>$.

8. Qosa H, Abuznait AH, Hill RA, Kaddoumi A. Enhanced brain amyloid- $\beta$ clearance by rifampicin and caffeine as a possible protective mechanism against Alzheimer's disease. J Alzheimers Dis. 2012;31(1):151-65. Available from: <http://www.pubmedcentral.nih.gov/articlerender.fcgi?artid $=3902015 \&$ tool $=$ pmcentrez\&rendertype $=$ abstract $>$.

9. Acquas E, Tanda G, Di Chiara G. Differential effects of caffeine on dopamine and acetylcholine transmission in brain areas of drug-naive and caffeine-pretreated rats. Neuropsychopharmacology. 2002;27(2):182-93. Available from: <http://www.ncbi.nlm.nih.gov/pubmed/12093592>.

10. Gevaerd MS, Takahashi RN, Silveira R, Da Cunha C. Caffeine reverses the memory disruption induced by intra-nigral MPTP-injection in rats. Brain Res Bull. 2001;55(1):101-6. Available from: <http://www.ncbi.nlm. nih.gov/pubmed/11427344>.

11. Korkotian E, Segal M. Release of calcium from stores alters the morphology of dendritic spines in cultured hippocampal neurons. Proc Natl Acad Sci U S A. 1999;96(21):12068-72. Available from: <http://www. pubmedcentral.nih.gov/articlerender.fcgi?artid=18413\&tool=pmcentr ez\&rendertype $=$ abstract $>$.

12. Prediger RD, Pamplona FA, Fernandes D, Takahashi RN. Caffeine improves spatial learning deficits in an animal model of attention deficit hyperactivity disorder (ADHD) - the spontaneously hypertensive rat (SHR). Int J Neuropsychopharmacol. 2005;8(4):583-94. Available from: $<$ http://www.ncbi.nlm.nih.gov/pubmed/15877934>.

13. Fredholm BB, Lindström K. Autoradiographic comparison of the potency of several structurally unrelated adenosine receptor antagonists at adenosine A1 and A(2A) receptors. Eur J Pharmacol. 1999;380(2-3):197202. Available from: <http://www.ncbi.nlm.nih.gov/pubmed/10513579>.

14. Cao C, Loewenstein DA, Lin X, Zhang C, Wang L, Duara R, et al. High blood caffeine levels in MCI linked to lack of progression to dementia. J Alzheimers Dis. 2012;30(3):559-72. Available from: <http://www.ncbi. nlm.nih.gov/pubmed/22430531>.

15. Amin N, Byrne E, Johnson J, Chenevix-Trench G, Walter S, Nolte IM, et al. Genome-wide association analysis of coffee drinking suggests association with CYP1A1/CYP1A2 and NRCAM. Mol Psychiatry. 2012;17(11):1116-29. Available from: <http://www.pubmedcentral.nih. gov/articlerender.fcgi?artid=3482684\&tool=pmcentrez\&rendertype $=$ abstract>.

16. Cornelis MC, El-Sohemy A, Campos H. Genetic polymorphism of the adenosine $\mathrm{A} 2 \mathrm{~A}$ receptor is associated with habitual caffeine consumption. Am J Clin Nutr. 2007;86(1):240-4.

17. Cornelis MC, Monda KL, Yu K, Paynter N, Azzato EM, Bennett SN, et al. Genome-wide meta-analysis identifies regions on 7 p21 (AHR) and 15q24 (CYP1A2) as determinants of habitual caffeine consumption. PLoS Genet. 2011;7(4):e1002033. Available from: <http://www. pubmedcentral.nih.gov/articlerender.fcgi? artid=3071630\&tool=pmcen trez\&rendertype $=$ abstract $>$.

18. Gatz M, Reynolds CA, Fratiglioni L, Johansson B, Mortimer JA, Berg S, et al. Role of genes and environments for explaining Alzheimer disease. Arch Gen Psychiatry. 2006;63(2):168-74. Available from: <http://www. ncbi.nlm.nih.gov/pubmed/16461860>.

19. Holtzman DM, Morris JC, Goate AM. Alzheimer's disease: the challenge of the second century. Sci Transl Med. 2011;3(77):77sr1. Available from: $<$ http://www.pubmedcentral.nih.gov/articlerender.fcgi?artid=3130546\& tool $=$ pmcentrez\&rendertype $=$ abstract $>$.

20. Kennedy JL, Farrer LA, Andreasen NC, Mayeux R, St George-Hyslop P. The genetics of adult-onset neuropsychiatric disease: complexities and conundra? Science. 2003;302(5646):822-6. Available from: <http://www. ncbi.nlm.nih.gov/pubmed/14593167>.

21. Bertram L, McQueen MB, Mullin K, Blacker D, Tanzi RE. Systematic meta-analyses of Alzheimer disease genetic association studies: the $\mathrm{Al}$ zGene database. Nat Genet. 2007;39(1):17-23. Available from: <http:// www.ncbi.nlm.nih.gov/pubmed/17192785>.

22. Szklarczyk D, Franceschini A, Kuhn M, Simonovic M, Roth A, Minguez P, et al. The STRING database in 2011: functional interaction networks of proteins, globally integrated and scored. Nucleic Acids Res. 2011 39(Database issue):D561-8. Available from: <http://www.pubmedcentral.nih.gov/articlerender.fcgi? artid=3013807\&tool=pmcentrez\&rend ertype $=$ abstract $>$.

23. Tanaka H, Nakazawa K, Arima M, Iwasaki S. Caffeine and its dimethylxanthines and fetal cerebral development in rat. Brain Dev. 1984;6(4):35561. Available from: <http://www.ncbi.nlm.nih.gov/pubmed/6496872>.

24. Lee WL, Anwyl R, Rowan M. Caffeine inhibits post-tetanic potentiation but does not alter long-term potentiation in the rat hippocampal slice. Brain Res. 1987;426(2):250-6. Available from: <http://www.ncbi.nlm. nih.gov/pubmed/3690324>.

25. Battram DS, Bugaresti J, Gusba J, Graham TE. Acute caffeine ingestion does not impair glucose tolerance in persons with tetraplegia. J Appl Physiol (1985). 2007;102(1):374-81. Available from: <http://www.ncbi. nlm.nih.gov/pubmed/17068214>.

26. Fredholm BB, Bättig K, Holmén J, Nehlig A, Zvartau EE. Actions of caffeine in the brain with special reference to factors that contribute to its widespread use. Pharmacol Rev. 1999;51(1):83-133. Available from: $<$ http://www.ncbi.nlm.nih.gov/pubmed/10049999>.

27. Björklund O, Halldner-Henriksson L, Yang J, Eriksson TM, Jacobson MA, Daré E, et al. Decreased behavioral activation following caffeine, amphetamine and darkness in A3 adenosine receptor knock-out mice. Physiol Behav. 2008;95(5):668-76. Available from: <http://www.ncbi. nlm.nih.gov/pubmed/18930070>.

28. Björklund O, Kahlström J, Salmi P, Fredholm BB. Perinatal caffeine, acting on maternal adenosine A1 receptors, causes long-lasting behavioral changes in mouse offspring. PLoS One. 2008;3(12):e3977. Available from: $<$ http://www.pubmedcentral.nih.gov/articlerender.fcgi?artid=2597749\& tool $=$ pmcentrez\&rendertype $=$ abstract $>$.

29. Lam FC, Liu R, Lu P, Shapiro AB, Renoir JM, Sharom FJ, et al. beta-Amyloid efflux mediated by p-glycoprotein. J Neurochem. 2001;76(4):1121-8. Available from: <http://www.ncbi.nlm.nih.gov/pubmed/11181832>

30. Abuznait AH, Cain C, Ingram D, Burk D, Kaddoumi A. Up-regulation of P-glycoprotein reduces intracellular accumulation of beta amyloid: investigation of P-glycoprotein as a novel therapeutic target for Alzheimer's disease. J Pharm Pharmacol. 2011;63(8):1111-8. Available from: <http:// www.pubmedcentral.nih.gov/articlerender.fcgi? artid=3163078\&tool $=p$ mcentrez\&rendertype $=$ abstract $>$.

31. Wostyn P, Van Dam D, Audenaert K, De Deyn PP. Increased cerebrospinal fluid production as a possible mechanism underlying caffeine's protective effect against Alzheimer's disease. Int J Alzheimers Dis. 2011;2011:617420. Available from: $<$ http://www.pubmedcentral.nih.gov/articlerender.fcgi?a $\mathrm{rtid}=3109764 \&$ tool $=$ pmcentrez\&rendertype $=$ abstract $>$. 